\title{
THE POTENTIAL ENERGY OF GEL POLYMER ELECTROLYTES FROM GUPPY (Poecilia reticulata) FISH WASTE FOR BATTERY APPLICATION
}

\author{
Khaulah Zakaria and Nik Aziz Nik Ali* \\ Faculty of Fisheries and Food Science, Universiti Malaysia Terengganu, Terengganu, Malaysia \\ *Corresponding author: nikaziz@umt.edu.my \\ http://doi.org/10.46754/umtjur.2021.07.002
}

\begin{abstract}
This study aims to determine the potential energy of gel polymer electrolytes from guppy (Poecilia reticulata) fish waste for battery applications through different parameters. The parameters include the number of fish, the number of days, and the battery's longevity. This experiment is underpinned by the concept of an electrical energy storage system of gel polymer electrolytes and urea as an energy carrier. The ammonia secreted by fish contains $\mathrm{NH}_{4}^{+}$which has positive hydrogen ion. The hydrogen ion in this element has the ability to produce electricity. This experiment involved tests on different batches of fish, with 5,10 and 15 fish in each respective batch. The wastewater samples were taken every two days, made into gel polymer electrolytes using agar, and inserted into the battery. The output voltage was recorded using a voltmeter, and each battery showed an increasing pattern of voltmeter reading against the number of days. For example, the highest voltage output was produced by a battery that used the wastewater sample with 15 fish on the 10th day, resulting in $0.45 \mathrm{~V}$. This is due to an increase of the amount of ammonia accumulated from fish waste within that 10 days. Batteries with the highest outputs of voltage from respective of number of fish were then taken for longevity test. The two weeks tests showed gradual decrease in the result due to many factors, including the ionic transference number and the disassociation of ionic particles in the electrolytes. The estimation of the battery longevity from water samples with 5, 10, and 15 fish were 71.47 days, 27.82 days and 34.44 days, respectively. This study proves that the gel polymer electrolytes from guppy, Poecilia reticulata has the potential to be used in batteries as an energy source.
\end{abstract}

Keywords: Undergraduate research, ornamental fish, guppy, fish waste, gel polymer electrolytes, battery.

\section{Introduction}

The world's demand for energy resources has increased tremendously to support the evergrowing modern industrial society on their increasing dependency on technology (Cho et al., 2015; Endo et al., 2017). It is unfortunate that the non-renewable energy source, which is fossil fuels, remains the core of global energy and is depleting at a very fast rate (Lieberei $\&$ Gheewala, 2017). The exploitation of these resources are also accompanied by the unsustainable method of harvesting that has been proven to cause irreversible harm to the environment in various occasions (Kongbuamai et al., 2021). Therefore, renewable energy is an appropriate response to these concerns and has gained multiple stakeholders' supports (Zou et al., 2016).
Renewable energy-driven technologies sourced from wind and solar have been widely discovered. However, these evergy resources are non-economical due to the high cost incurred and service inability during ofsource periods (Mensah-Darkwa et al., 2019; Zhang et al., 2014. Energy can be generated from stationary electrical energy storage (EES) systems as an alternative to impractical direct energy conversion technologies. Among various EES systems, electrochemical storage such as batteries has an advantage in being more efficient than the other systems because it is more practical for customer usage (Cho et al., 2015). There are many potentials of innovation through this system as the separator part in the battery that carries the energy sources can be substituted with various types of electrolytes (Song et al., 1999). As a result of Stanford 
University's research, low-cost batteries with electrolytes made from urea from fertilizers have been developed. It has proven its potential to replacethe conventional storage system of energy (Jackie, 2017).

The usage of urea as an energy carrier might become the remedy for the problem of cost and availability in nature compared to the others. Urea can be found in fish waste as the fish excrete ammonia (Francis-floyd et al., 2012; Meade, 1985). Specifically,ammonia exists when nitrogen and hydrogen elements are bonded together. The hydrogen elements in the waste can be converted into energy and have the potential to produce electricity (King \& Botte, 2011). Fish waste that contains ammonia may also contribute to the nitrogenous wastes in the environment when it is accumulated and not appropriately addressed (Kawasaki, 2016; Lazzari \& Baldisserotto, 2008).
Due to the increase of nitrogenous waste in the environment, the waste management of farm fish has gained concerns from stakeholders as the industry continues to grow from various perspectives, specifically for the ornamental fish. Ornamental fish are gaining popularity as their economic value rises year after year. Therefore, the farmers are constantly looking for ways to maximize their production with minimal space and resources that might lead to the high concentration of nitrogenous waste in the water ecosystem when thrown away (Livengood \& Chapman, 2007; Ng, 2016), as high ammonia concentration can potentially be utilized as energy sources, and if practised, the waste from the industry can be reduced. Thus, the purpose of this research, which focuses on the potential energy of gel polymer electrolytes from ornamental fish, is to demonstrate the viability of using fish waste as a source of energy for battery applications and to assess its longevity (Cho et al., 2015; Lan et al., 2010; Zamfirescu \& Dincer, 2009).

\section{Materials and Methods}

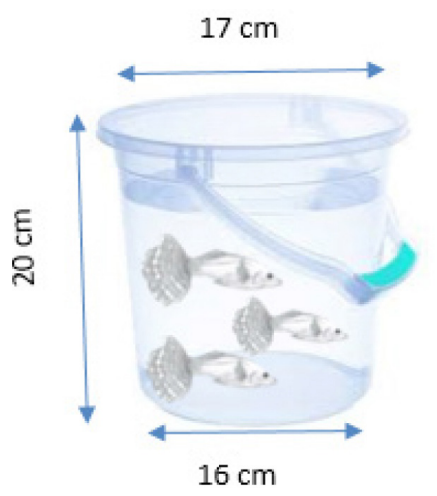

Figure 1: The experimental setup

Figure 1 shows the experimental setup for this study while tending the fish for ten (10) days. The number of fish used were five (5), ten (10) and fifteen (15) fish per tank. The size of the tank, volume of water and quantity of feed per fish are fixed, where the dimensions of the pails were $20 \mathrm{~cm}$ in height, with $17 \mathrm{~cm}$ opening and $16 \mathrm{~cm}$ base width with volume of water being set as 4.6 litres and the amount of feed given is $3 \%$ over the fish weight, twice daily. Smallsized Poecilia reticulata with body lengths of 2 to 3 centimetres were used during this study. The water was not changed during the tending period until sample water has been taken. In addition, $75 \mathrm{ml}$ wastewater was taken every two days to be made as gel polymer electrolytes for the battery. 
Figure 2 shows the battery design used in this study. The anode electrodes are made from aluminium and the cathode electrode are made from copper. The casings are cylinder-shaped with a diameter of $2.5 \mathrm{~cm}$ and height of 15 $\mathrm{cm}$. The gel polymer electrolytes consist of 25 $\mathrm{ml}$ wastewater with 0.5 grams of agar powder. Both ingredients were mixed, heated for the agar to melt, and mixed with the rest of $46 \mathrm{ml}$ of wastewater for the battery. Initial $25 \mathrm{ml}$ was taken for the agar mixture to reduce the heat loss during heating process. Next, the mixtures were poured and rested in room temperature until the gel hardens. The batteries were then sealed, and the voltmeter readings of the battery were recorded.

The battery's energy output was recorded using a voltmeter following the study's objectives using different fish and number of days as the studied variables. The batteries with the highest voltage output values from the respective number of fish were taken for a longevity test for 14 days. The battery's voltmeter readings for every two days were measured using digital multimeter Pro's Kit MT-1820. The readings were taken on 5 different days from each tank of fish, specifically on the $2^{\text {nd }}, 4^{\text {th }}$, $6^{\text {th }}, 8^{\text {th }}$ and the $10^{\text {th }}$ day. The samples were also taken from the tank with the following number of fish; five (5), ten (10) and fifteen (15). Three readings were recorded for each sample and the average is taken for further analysis. The data were tabulated and expressed to estimate the longevity of each battery. Hypothetically, as the number of days and fish increases, the voltmeter reading will increase due to the increase in the amount of waste excreted, indicating higher energy stored in the battery. T-test analysis with alpha value range of $0.05(\alpha=0.05)$ was conducted using Microsoft Excel for this study to compare the significant differences between each of the group.

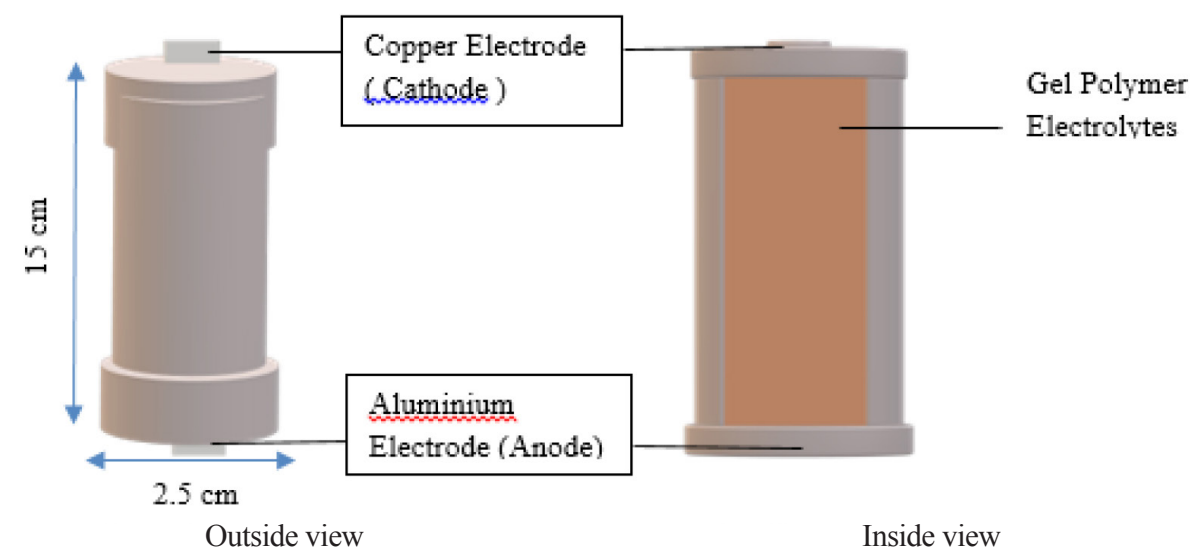

Figure 2: The battery design

\section{Results and Discussion}

\section{The output voltage of the battery}

The result of output voltage from all types of batteries was recorded and is illustrated in Figure 4. From this figure, the result of each battery can be differentiated. The battery results for wastewater from the tank with five fish (5) are represented in blue. The orange-coloured bar in Figure 4 represents the result for the battery from the tank with ten fish (10) wastewater sample. At the same time, the grey coloured column represents the result for the battery from the tank with fifteen fish (15) wastewater sample. The results indicate that the highest output voltage readings for all wastewater sample-based batteries was yielded on the $10^{\text {th }}$ day, which is $0.45 \mathrm{~V}$. Overall, the output voltage for all batteries gradually increased as the number of days increases. 
Moreover, the p-value of the T-test against each type of battery is also significant. For example, the $\mathrm{p}$-value from the t-Test result of analysis of wastewater taken from 5 fish against ten(10) fish is 0.019189 , 5 fish against fifteen (15) fish is 0.000429 , and lastly, ten (10) fish against fifteen (15) fish resulted in a p-value of 0.013763 . These results show a significant difference between all types of batteries when compared to each other. Therefore, three batteries with the highest output voltage are chosen for the longevity test.

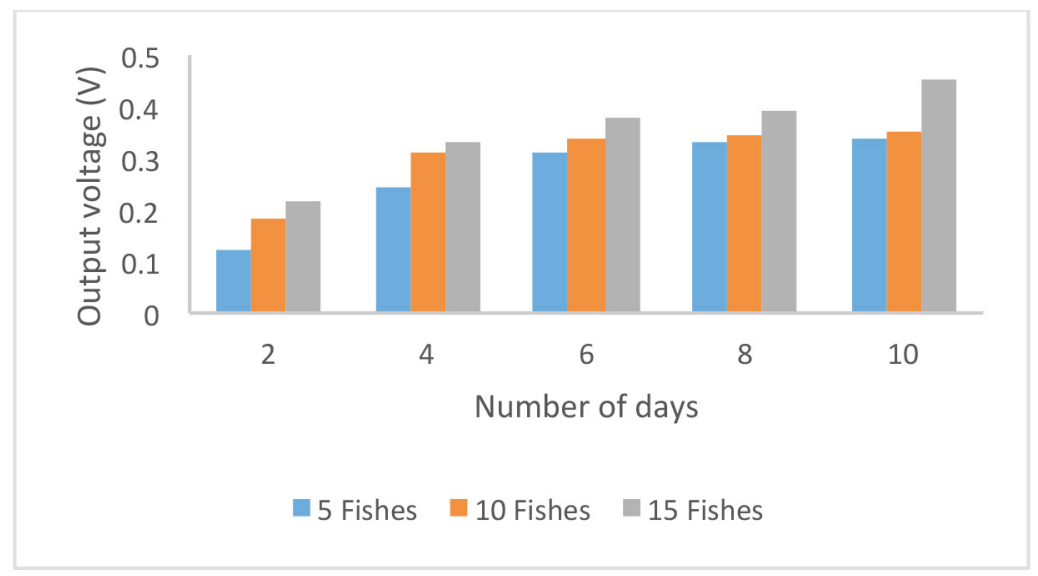

Figure 3: The output voltage of the batteries of five (5) fish, ten (10) fish and fifteen (15) fish against the number of days

\section{Longevity test}

Figure 5 shows the result of the longevity test for three batteries. From the figure, the readings of each battery differ as depicted in the pattern. The battery that used wastewater from five(5) fish samples as the gel polymer electrolytes yielded battery readings that fluctuated for the first six (6) days before becoming constant. Meanwhile, for the battery that used wastewater from ten (10) fish samples, the reading rose to $0.48 \mathrm{~V}$ on the second day and gradually decreases after that. Lastly, the battery that used wastewater from fifteen (15) fish samples as the separator gradually decreases against the number of days. . It can also be seen that the batteries' final readings are close to one another, which are $0.241 \mathrm{~V}$, $0.217 \mathrm{~V}$, and $0.218 \mathrm{~V}$ for five (5) fish, ten (10) fish and fifteen (15) fish battery respectively. The T-Test statistical analysis comparing the output voltage by different types of battery against the number of days showed significant difference between each battery used. The p-value of five (5) fish battery against ten (10) fish battery is 0.03064 , five (5) fish battery against fifteen (15) fish battery is 0.00223 , and ten (10) fish battery against fifteen (15) fish battery is 0.00127 . The significant $\mathrm{p}$-values proved that the number of fish affects the output voltage of batteries.

Furthermore, statistical data analysis was also run for each output voltage result against the number of days. The p-values are mostly insignificant for the result of output voltage in four days, and the significance started to show as the lifetime of the battery increases. For references to prove this pattern, the highest p-value recorded was the p-value of batteries output voltage on the $4^{\text {th }}$ days against the output voltage of the $10^{\text {th }}$ day, which is 0.46031 . In contrast, the lowest p-value was recorded between the output voltage of day twelfth (12) against day 0 , which resulted in 0.00442 . 


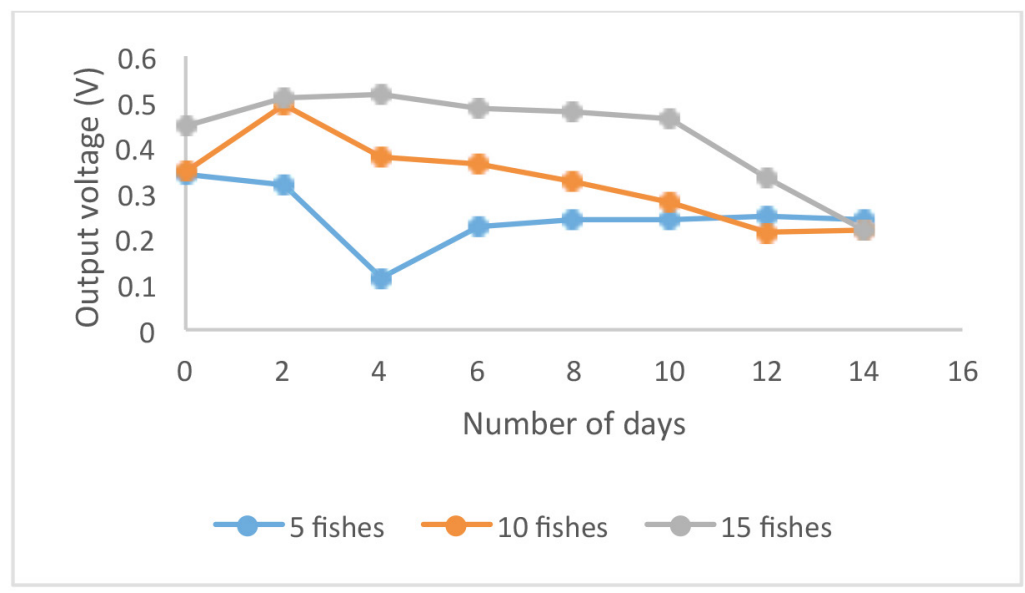

Figure 4: The comparison on longevity test of the battery

With two differentiating variables, the battery's energy output was successfully measured from the wastewater of Poecilia reticulata species that were tended for ten (10) days.. The first two variables used to observe the electrical output were the number of fish and the number of days. According to Figure 4, the output voltage pattern against both variables was the same, with output voltage readings increasing linearly. This is because as the days passed, the decomposing wastewater and fish food gradually produced ammonia. The amount of ammonia secreted, which contains bonded nitrogen and hydrogen molecules, increased with waste accumulation. Hydrogen in the waste can be converted into energy and the ability to produce electricity. In this practice, ammonia from fish waste can be utilized as another energy source, and if practised, the waste from the industry can also be reduced. Factors such as the size of fish, number of feed, time for feeding and amount of water used could affect the amount of waste in the water(Edeghe \& Ajah, 2018). For such reasons, these influencing factors were controlled in this study to ensure better results. The findings proved that electrical energy could be generated by using gel polymer electrolytes obtained from guppy, Poecilia reticulata fish waste. The number of days of waste accumulation significantly affected the production of energy from the battery.
Figure 5 shows that all three batteries' longevity test readings showed insignificant reading changes within the interval days. Simultaneously, the battery's longevity from gel polymer electrolytes can also be estimated through the linear equation. From the estimation, the battery with five (5) fish wastewater sample as the gel polymer electrolytes can last up to 71.47 days, the battery of ten (10) fish wastewater sample with can last up to an estimation of 27.82 days, and lastly, the battery that used the fifteen (15) fish wastewater samples up to 34.44 days. Based on the pattern, it can also be seen that as the number of fish increases, the particles of positive ions in the electrolytes can be more unstable as the days passed. There are many factors of how the energy can be lost, such as the influence of other foreign particles, temperature and the ionic strength of the fluid to the electrical current (Cho et al., 2015; Song et al., 1999; Zhang et al., 2014). Moreover, the movement of electrical charges between the cathode and anode of the battery will continue to take place even when the electrolytes are stored in the battery. Other than that, electrolytes' conductivity also depends on other properties such as ionic transference number and ion mobilities, structure formation by ion association and solvation, and viscosity and state of matter. 


\section{Conclusion}

In conclusion, the voltage output from the fish waste of Poecelia reticulata produced different results based on the number of fish (which $\mathrm{N}=5,10,15$ ) with the highest voltage recorded for the battery that used fifteen (15) fish wastewater sample as the gel polymer electrolytes that produced $0.45 \mathrm{~V}$ on the $10^{\text {th }}$ day. The longevity test results showed that the battery that used five (5) fish wastewater samples would last the longest with the estimation of 71.47 days. Thus, it can be concluded that the energy output of batteries was dependent on the number of fish and the period of time.

\section{Acknowledgements}

I thank my supervisor, Ts. Dr Nik Aziz for his guidance and endless patience while supervising this project. I also thank my family and friends for their support and assistance throughout the project implementation. The feedback from lecturers from the Faculty of Fisheries and Food Science, Universiti Malaysia Terengganu, is also appreciated.

\section{References}

Cho, J., Jeong, S., \& Kim, Y. (2015). Commercial and research battery technologies for electrical energy storage applications. Progress in Energy and Combustion Science, 48, 84-101. https:// doi.org/10.1016/j.pecs.2015.01.002

Edeghe, A., \& Ajah, P. (2018). Effect of feed and stocking density on the growth performance of Clarias gariepinus (Burchell, 1822) reared intensively in fiberglass and concrete ponds in Calabar, South Eastern Nigeria.

Endo, A., Tsurita, I., Burnett, K., \& Orencio, P. M. (2017). A review of the current state of research on the water, energy, and food nexus. Journal of Hydrology: Regional Studies, 11, 20-30. https://doi.org/10.1016/j. ejrh.2015.11.010

Francis-floyd, R., Watson, C., Petty, D., \& Pouder, D. B. (2012). Ammonia in Aquatic
Systems. Fisheries and Aquatic Sciences Department, Florida Cooperative Extension Service, Institute of Food and Agricultural Sciences, University of Florida., May 2014, $1-4$.

Jackie, F. (2017, February 7). Stanford engineers create a low-cost battery for storing renewable energy. Stanford News. https:// news.stanford.edu/2017/02/07/stanfordengineers-create-low-cost-battery-storingrenewable-energy/

Kawasaki, N. (2016). Release of Nitrogen and Phosphorus from Aquaculture Farms to Selangor River, Malaysia. International Journal of Environmental Science and Development, 7(2), 113-116. https://doi. org/10.7763/IJESD.2016.V7.751

King, R. L., \& Botte, G. G. (2011). Hydrogen production via urea electrolysis using a gel electrolyte. Journal of Power Sources, 196(5), 2773-2778. https://doi. org/10.1016/j.jpowsour.2010.11.006

Kongbuamai, N., Bui, Q., \& Nimsai, S. (2021). The effects of renewable and nonrenewable energy consumption on the ecological footprint: The role of environmental policy in BRICS countries. Environmental Science and Pollution Research, 28(22), 2788527899. https://doi.org/10.1007/s11356-02112551-3

Lan, R., Tao, S., \& Irvine, J. T. S. (2010). A direct urea fuel cell-Power from fertilizer and waste. Energy and Environmental Science, 3(4), 438-441. https://doi.org/10.1039/ b924786f

Lazzari, R., \& Baldisserotto, B. (2008). Nitrogen and phosphorus waste in fish farming. Boletim Do Instituto de Pesca, 34(4), 591-600.

Lieberei, J., \& Gheewala, S. H. (2017). Resource depletion assessment of renewable electricity generation technologies - Comparison of life cycle impact assessment methods with focus on mineral resources. The International Journal of Life Cycle Assessment, 
22(2), 185-198. https://doi.org/10.1007/ s11367-016-1152-3

Livengood, E. J., \& Chapman, F. A. (2007). The Ornamental Fish Trade: An Introduction with Perspectives for Responsible Aquarium Fish Ownership. IFAS Extension, 1-8.

Meade, J. W. (1985). Allowable ammonia for fish culture. Progressive Fish-Culturist, 47(3), 135-145. https://doi.org/10.1577/15488640(1985)47<135:AAFFC $>2.0 . C O ; 2$

Mensah-Darkwa, K., Zequine, C., Kahol, P. K., \& Gupta, R. K. (2019). Supercapacitor Energy Storage Device Using Biowastes: A Sustainable Approach to Green Energy. Sustainability, 11(2), 1-22.

$\mathrm{Ng}, \mathrm{C}$. (2016). The ornamental freshwater fish trade in Malaysia. UTAR Agriculture Science Journal, 2(4), 7-18.

Song, J. Y., Wang, Y. Y., \& Wan, C. C. (1999). Review of gel-type polymer electrolytes for lithium-ion batteries. Journal of Power Sources, 77(2), 183-197. https://doi. org/10.1016/S0378-7753(98)00193-1

Zamfirescu, C., \& Dincer, I. (2009). Ammonia as a green fuel and hydrogen source for vehicular applications. Fuel Processing Technology, 90(5), 729-737. https://doi. org/10.1016/j.fuproc.2009.02.004

Zhang, Z., Zuo, C., Liu, Z., Yu, Y., Zuo, Y., \& Song, Y. (2014). All-solid-state Al-air batteries with polymer alkaline gel electrolyte. Journal of Power Sources, 251, 470-475. https://doi.org/10.1016/j.jpowsour.2013.11.020

Zou, C., Zhao, Q., Zhang, G., \& Xiong, B. (2016). Energy revolution: From a fossil energy era to a new energy era. Natural Gas Industry B, 3(1), 1-11. https://doi. org/10.1016/j.ngib.2016.02.001 
